Research Paper:

\title{
Traumatic Spinal Cord Injuries Due to Motor Vehicle Accidents
}

\author{
Sasan Andalib ${ }^{1,2,3}$, Zahra Mohtasham-Amiri ${ }^{1}$, Shahrokh Yousefzadeh-Chabok ${ }^{1,2,3^{*}}$, Alia Saberi ${ }^{2}$, Mohammadreza Emamhadi ${ }^{4}$, Leila \\ Kouchakinejad-Eramsadati ${ }^{1}$, Zohreh Norouzi $^{1}$, Hadiseh Shokat ${ }^{1}$, Sara Sayad-Fathi ${ }^{2}$, Samaneh Ghorbani-Shirkouhi ${ }^{2} \mathrm{O}$
}

1. Guilan Road Trauma Research Center, Poursina Hospital, School of Medicine, Guilan University of Medical Sciences, Rasht, Iran

2. Neuroscience Research Center, Poursina Hospital, School of Medicine, Guilan University of Medical Sciences, Rasht, Iran

3. Department of Neurosurgery, Poursina Hospital, School of Medicine, Guilan University of Medical Sciences, Rasht, Iran

4. Brachial Plexus and Peripheral Nerve Injury Center, Guilan University of Medical Sciences, Rasht, Iran

\begin{tabular}{|l|l}
$\begin{array}{c}\text { Use yourdevice to scan } \\
\text { and read the article online }\end{array}$ & $\begin{array}{l}\text { Let et al. Traumatic Spinal Cord Injuries Due to Motor Vehicle Accidents. Iran J Neurosurg. 2018; 4(4):213-218. http://dx.doi. } \\
\text { L, et andalib S, Mohtasham-Amiri Z, Yousefzadeh-Chabok Sh, Saberi A, Emamhadi M, Kouchakinejad-Eramsadati } \\
\text { org/10.32598/irjns.4.4.195 }\end{array}$ \\
d. http://dx.doi.org/10.32598/irjns.4.4.195
\end{tabular}

(1) $0(3)$

Article info:

Received: 13 May 2018

Accepted: 23 Aug 2018

Available Online: 01 October 2018

Keywords:

Spine trauma, Spinal cord

injury, Motor vehicle

accident, $\mathrm{SCl}$

\section{ABSTRACT}

Background and Aim: Spine trauma is an important health problem. Traumatic Spinal Cord Injury (SCl) due to Motor Vehicle Accident (MVA) might have a different epidemiologic pattern in Guilan province of Iran owing to its geographical characteristics. Therefore, the present study was conducted to the study epidemiology of $\mathrm{SCl}$ injuries due to road accidents in a trauma referral center in Guilan.

Methods and Materials/Patients: In this cross-sectional study, we used data SCI registry of Poursina Hospital. All the patients with spine trauma, due to MVA, hospitalized in the trauma center of Poursina Hospital, Rasht, Guilan, Iran between March 2015 and March 2018 were studied.

Results: A total of 127 patients with spine trauma due to MVA were reviewed. The Mean $\pm S D$ age of patients was $38.27 \pm 16.22$ years. We observed that $93.7 \%, 1.6 \%$, and $4.7 \%$ of the patients had initial Glasgow Comma Scale (GCS $\geq 13,9 \leq \mathrm{GCS} \leq 12$, and GCS $<9$, respectively). SCls were found several anatomical regions including cervical $(n=54,42.5 \%)$, lumbar $(n=39,30.7 \%)$, thoracic $(n=23,18.1 \%)$, thoracic and lumbar $(n=7,5.5 \%)$, thoracic and cervical $(n=3,2.4 \%)$, and lumbar and cervical $(n=1$, $0.8 \%$ ) regions. Evaluated by Glasgow Outcome Scale (GOS), good recovery, moderate disability, severe disability, vegetative state, and death were found in $114(91.2 \%), 4(3.1 \%), 4(3.1 \%), 1(0.8 \%)$, $2(1.6 \%)$ of the patients, respectively. Two patients were discharged by their personal contest.

Conclusion: Spine trauma due to MVA is mostly seen in the young. SCl due to such trauma is mostly found in the cervical region. Good recovery was seen in most of the subjects.

\section{* Corresponding Author:}

Shahrokh Yousefzadeh-Chabok, MD.

Address: Guilan Road Trauma Research Center, Poursina Hospital, School

of Medicine, Guilan University of Medical Sciences, Rasht, Iran

Tel: +98 (13) 33311472

E-mail: neurosurgery97@yahoo.com 


\section{Highlights}

- Out of 127 MVA-induced TSCl patients, 99 (78\%) were male and 28 (22\%) were female.

- Accident with cars/pickup trucks was the main cause of TSCl among patients (76.9\%).

- Drivers and passengers made up $72.1 \%(n=80)$ and $27.9 \%(n=31)$ of the patients, respectively.

- The most and least common places for accidents to occur were cities (84.3\%) and highways (5.5\%).

- The most and least common anatomical regions injured due to MVA were cervical (42.5\%) and lumbar-cervical regions (0.8\%).

- Ninety-three patients (83.8\%) used no safety device and 18 (16.1\%) used safety belts or helmets.

- The GCS $\geq 13$ was reported for $93.7 \%$ of patients; $4.7 \%$ had GCS $<9$, and $1.6 \%$ experienced $9 \leq \mathrm{GCS} \leq 12$.

- According to Glasgow outcome scale results, good recovery, moderate disability, severe disability, vegetative state, and death were observed in $91.2 \%, 3.1 \%, 3.1 \%, 0.8 \%, 1.6 \%$ of patients, respectively.

\section{Plain Language Summary}

Traumatic Spinal Cord Injuries (TSCls) are health-threatening complications mostly occur due to Motor Vehicle Accidents (MVAs). In order for health system to make plans for TSCl patients' management, it is important to identify epidemiologic pattern of accidents in different geographical regions. Therefore, thorough study of the factors predicting the incidence, types, and locations of accidents and also the types of the associated injuries could be preventive. In the present cross-sectional study, we evaluated TSCI patients' data by using traumatic spinal cord injury (SCI) registry of Poursina Hospital. All the patients who experienced spinal cord injuries due to MVAs in Guilan province between March 2015 and March 2018, were enrolled in this study. Among 127 patients with the Mean \pm SD age of $38.27 \pm 16.22$ years, 91 and 36 had collision and overturn accidents, respectively. Among these patients, majority (76.9\%) experienced $\mathrm{SCl}$ as a result of car/pickup trucks accident, and the accidents were predominantly occurred in cities. Although all of the study subjects suffered from $\mathrm{SCl}$ at least in one of their spinal regions, $93.7 \%$ of them had good initial Glasgow Comma Scale (GCS $\geq 13$ ). Moreover, indicated by Glasgow Outcome Scale (GOS), we found that $91.2 \%$ of the patients had good recovery. Based on our findings, it can be suggested that MVA-induced SCl is mostly observed in the young patients, and the most affected spinal region is cervical region.

\section{Introduction}

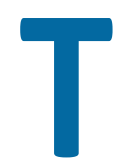

raumatic Spinal Cord Injury $(\mathrm{SCl})$ is an important health problem imposing an enormous financial burden upon health care system. $\mathrm{SCl}$ is disabling and is mostly seen in the young [1]. Prevention of $\mathrm{SCl}$ is critical because it is incurable. Understanding epidemiological findings of $\mathrm{SCl}$ is vital for prevention and planning clinical services [2]. SCl can result in serious disability and cause dysfunctions in many organs, such as respiratory, gastrointestinal, urinary, and autonomic nervous system, skin, bone, and joints. These may in turn lead to movement disorders, serious complications, and a high mortality rate during both acute and chronic stages of SCI [3]. Almost 17,500 new SCl occur in the United States each year [4].

The mechanisms of these injuries may be traumatic or nontraumatic [4]. The three most common causes of traumatic $\mathrm{SCl}$ are transportation (especially road traffic crashes), falls, and violence (including self-harm), respectively. Across all regions, sport and leisure activities account for less than $10 \%$ of all cases of traumatic SCl [5]. Studies suggest that the leading causes of nontraumatic spinal cord injuries are neoplastic tumors and degenerative conditions of the spinal column, followed by vascular and autoimmune disorders, tuberculosis and other infectious diseases, congenitally and genetically such as spina bifida [5]. 
The symptoms of spinal cord lesion depend on the extension of the injury or non-traumatic cause. They include loss of sensory or motor control of the lower limbs, trunk and the upper limbs, and loss of autonomic regulation of body, disrupting breathing, heart rate, blood pressure, temperature control, bowel and bladder control, and sexual function. The higher the level of $\mathrm{SCl}$, the greater the extent of disability. Cervical SCl commonly causes sensory and motor deficit (paralysis) in arms, body, and legs, a condition called tetraplegia or quadriplegia.

Patients with lesions at level of C4 or higher may need to use a ventilator to breathe, because the lesion directly affects the autonomic control. Thoracic SCl typically causes sensory and/or motor loss in the trunk and legs, which is called paraplegia. Lumbar $\mathrm{SCl}$ commonly causes sensory and motor loss in the hips and legs. All forms of $\mathrm{SCl}$ may also give rise to chronic pain. The $\mathrm{SCl}$ extension and severity of sensory, motor and autonomic system loss depends on the level of $\mathrm{SCl}$, and also on whether the lesion is complete or incomplete. According to the International Standards for Neurological Classification of SCI published by the American Spinal Injury Association (ASIA), a complete $\mathrm{SCl}$ is defined as if there is no sensory and motor function at $\mathrm{S4}-\mathrm{S} 5$, while in incomplete $\mathrm{SCl}$, some sensory and or motor function is preserved below the level of injury, such as in the lowest sacral segments (S4S5) which can still cause severe impairments [5].

Studies have shown that people with $\mathrm{SCl}$ die 2 to 5 times as early as people without $\mathrm{SCl}$. Causes of death in $\mathrm{SCl}$ vary from urinary tract and cardiovascular disease (mostly ischemic heart disease) and respiratory complications. Causes of death in $\mathrm{SCl}$ patients are similar to those in the general population due to improved early medical care, specialized rehabilitation and regular follow-up visits. However, the longevity of patients with $\mathrm{SCl}$ is still less than that of general population [6].

Mortality of SCl patients is influenced by neurological level of injury (tetraplegic patients die earlier than paraplegics and cervical $\mathrm{SCl}$ s are associated with higher mortality than lumbar SCls), completeness of the $\mathrm{SCl}$, old age, presence of multisystem trauma, high-energy injury mechanisms. Death is more probable in $\mathrm{SCl}$ patients during the first year(s) subsequent to injury. Annual mortality rates are high, with 3.8\% of patients dying in the first year after injury, $1.6 \%$ in the second year and then $1.2 \%$ for every year thereafter [5-7]. Men are at higher risk of $\mathrm{TSCl}$, compared to women however, the gender ratio vary in different regions [2]. The mortality rate of traumatic $\mathrm{SCl}$ in men is 3 times higher than in women and the severity of injury in $\mathrm{TSCl}$ is approximately 5 times higher than in nontraumatic $\mathrm{SCl}[8]$.
Moreover, average age of patients with $\mathrm{SCl}$ varies in different countries. More recently, several studies have reported an increase in average age of patients with $\mathrm{SCl}$ in the USA as the median age of general population of the USA has increased by approximately 9 years since the mid-1970 [9]. In the National Spinal Cord Injury Statistical Centre Database of USA, the average age of patients with $\mathrm{SCl}$ has increased from 28.7 years during the 1970 s to 41 years since 2005 [9]. The proportion of people who are injured after the age of 60 increased from $5 \%$ to $13 \%$ during the same period [10]. In a retrospective study in Tehran from 2010 to 2011 the mean age of patient with $\mathrm{TSCl}$ was $33.2 \pm 14.3$ years [11]. Children are less likely to be affected by spinal injuries, compared to the adult [12].

It has been demonstrated that the motorcycle riders have more severe injuries, more extremity traumas and a high mortality rate than car drivers and the patterns of spinal injury are consistent with forced hyperflexion of thoracic spine in that, in car occupants, prominence of cervical injuries and higher incidence of neck and facial injuries may reflect abdominothoracic seat belt restraint [13].

Post-SCl disabilities place a huge burden on the patient and their family, as well as being heavy financial burden on the society and the health care system [14]. The differences in culture and climate and also urban texture can have a direct impact on the incidence of $\mathrm{SCl}$ and even their types and levels [15]. Road traffic crashes are the leading cause of traumatic $\mathrm{SCl}$, according to WHO [5]. In Iran, the prevalence of road traffic crashes decrease from north to south of Iran, with the highest pooled road traffic crashes rate in Guilan province $(79.80 \%$ [95\% Cl=79.1\%-80.5\%]) [16]. However, only a few studies on the epidemiology of traumatic $\mathrm{SCl}$. Epidemiology of $\mathrm{SCl}$ due to road crashes is a less divulged topic in Iran. In addition, Guilan attracts travelers because of climatic conditions, especially in Nowruz holidays and summer, it appears to have a different pattern in terms of road accidents, and presumably $\mathrm{SCl}$. Therefore, the present study was conducted to study epidemiology of $\mathrm{SCl}$ injuries due to road accidents in a trauma referral center in Guilan.

\section{Methods \& Materials/ Patients}

In this cross-sectional study, we used data $\mathrm{SCl}$ registry of Poursina Hospital. All the patients with spine trauma due to motor MVA, confirmed by CT scan or MRI, who had been hospitalized in the trauma center of Poursina Hospital, Rasht, Guilan, Iran between March 2015 and March 2018, were studied. Data regarding demographic information, type of vehicle in accident, anatomical location of $\mathrm{SCl}$, accident location, the type of the injured person in the accident, accident type, use of safety devices, Glasgow Comma Scale 
(GCS) level, associated cardiac and respiratory diseases, complications during hospitalization, pain, duration of ICU stay, comorbid injuries and Glasgow Outcome Scale (GOS) during discharge were extracted. Descriptive statistics were calculated.

\section{Results}

A total of 127 patients with TSCl injuries due to MVA were reviewed. The Mean \pm SD age of patients was $38.27 \pm 16.22$ years. Seventy-eight percent of the patients were male $(n=99)$ and $22 \%$ were female $(n=28)$. Male/female ratio was 3.54: 1 . Ninety-one patients (71.7 \%) and 36 (28.3\%) patients had collision and overturn accidents, respectively. The patients had accident with car/pickup truck (76.9\%), objects $(15.4 \%)$, truck $(4.4 \%)$, motorcycle $(2.2 \%)$, and transient object/animal (1.1\%). Sixty-two (48.8\%) patients were car passengers; 41 (32.3\%) patients were motorcyclists; 16 (12.6\%) patients were pedestrians; 4 (3.1\%) patients were cyclist; one $(0.8 \%)$ patient was bus passenger, two patients (1.6\%) were pickup truck passenger; and one (0.8\%) patient was truck passenger. Drivers and passengers accounted for $72.1 \%(n=80)$ and $27.9 \%(n=31)$ of the patients, respectively. There were 107 accidents (84.3\%) in cities, 13 accidents $(10.2 \%)$ in rural places, and 7 accidents (5.5\%) in highways.

SCls were found several anatomical regions including cervical $(n=54,42.5 \%)$, lumbar $(n=39,30.7 \%)$, thoracic $(n=23$, $18.1 \%)$, thoracic and lumbar $(n=7,5.5 \%)$, thoracic and cervical ( $n=3,2.4 \%)$, and lumbar and cervical $(n=1,0.8 \%)$ regions. Ninety-three patients (83.8\%) used no safety device; 17 patients (15.3\%) used safety belt; and only 1 patient (0.8\%) used crash helmet. GCS $\geq 13$ was scored in $93.7 \%$ of patients; $4.7 \%$ of the patients had GCS $<9$, and $1.6 \%$ experienced $9 \leq \mathrm{GCS} \leq 12$ (Figure 1). One hundred patients $(94.5 \%)$ showed

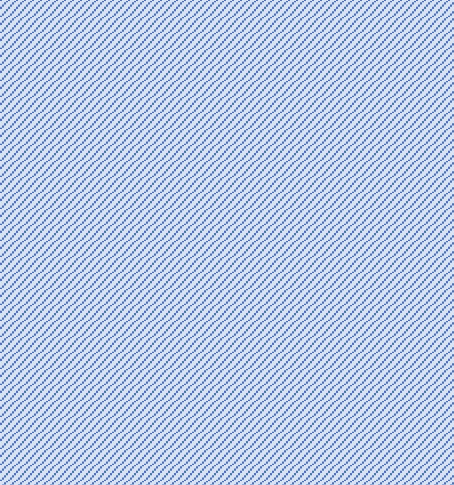

aCS $\geq 13$

- $9 \leq \mathrm{GCS} \leq 12$

$-\mathrm{GCS}<9$

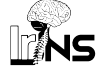

Figure 1. GCS in the patients with traumatic spine in motor vehicle accidents no cardiovascular disease; five patients (3.9\%) experienced high blood pressure; one patient $(0.8 \%)$ had stroke; and one patient $(0.8 \%)$ had palpitation. One hundred twenty-six patients (99.2 \%) showed no respiratory disease; even so, only one patient $(0.8 \%)$ had asthma. Most of the patients (124 patients) showed no complications after hospitalization; two patients had fever; and one patient suffered from CSF leakage $(97.6 \%, 1.6 \%, 0.8 \%$ respectively).

According to VAS, Mean \pm SD pain score of the patients was $5.39 \pm 1.14$. Mean $\pm S D$ duration of hospitalization in ICU was $6.40 \pm 10$ days (Median=2, Range=35). Evaluated by GOS, good recovery, moderate disability, severe disability, vegetative state, and death were seen in 114 (91.2\%), 4 (3.1\%), 4 (3.1\%), $1(0.8 \%), 2$ (1.6\%) patients, respectively (Figure 2). Two patients were discharged by their personal Consent.

\section{Discussion}

The aim of this investigation was to evaluate epidemiology of traumatic spine injuries due to motor vehicle accidents during in Poursina Hospital of Guilan. Poursina Hospital is a referral therapeutic center for trauma. According to the results of the present study, the Mean $\pm S D$ of age of patients was $38.27 \pm 16.22$ years. In a hospital-based investigation in Tehran, the Mean $\pm S D$ of age was $33.2 \pm 14.3$ years [11]. In a cross-sectional study in China the Mean $\pm S D$ age was $40.5 \pm 13.8$ years [17].

These results show that traumatic spine is mostly seen in the young, rather than in the elderly. In this study the male/ female ratio was 3.54: 1. In Iran, Taghipoor et al. and Fakharian et al. $[18,19]$ reported a male/female ratio of $4: 1$ and 3.7: 1, respectively. In agreement with other studies [17, 20], males were shown to suffer from $\mathrm{SCl}$ more than females in our investigation. Type of accident for $71.7 \%$ of the patients
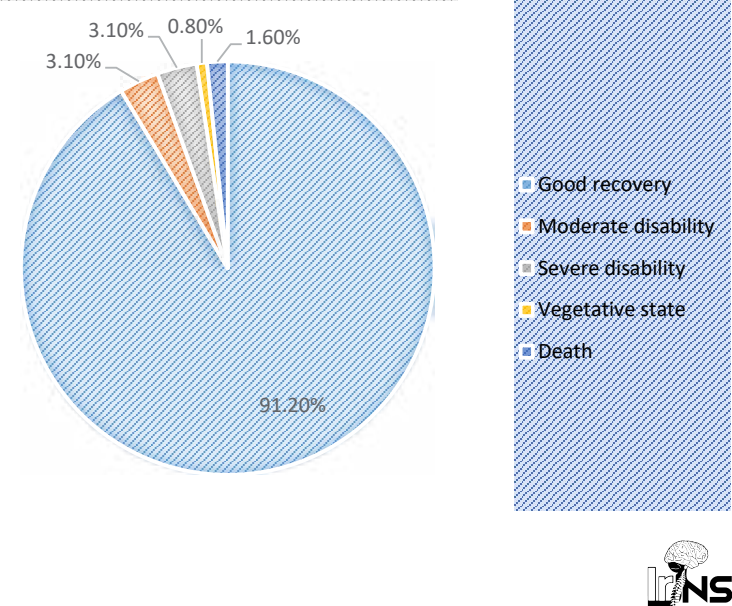

Figure 2. GOS in the patients with traumatic spine in motor vehicle accidents 
was collision; nevertheless, $28.3 \%$ of them overturned. Thurman et al. showed that during 1989-1991, among car and truck passengers with $\mathrm{SCl}, 70 \%$ were involved in a vehicle rollover [21]. In the present study, the most common objects to hit were car/pickup truck (76.9\%) and objects (15.4\%). Car passengers, motorcyclists and pedestrians were involved in $48.8 \%, 32.3 \%$, and $12.6 \%$ of accidents leading to traumatic spine. In the Thurman's study [21], 49\% of persons injured in motor vehicle accidents were automobile passengers; $25 \%$ were occupants of light trucks, including pickup trucks, vans, and utility vehicles; $8.2 \%$ of the patients were motorcyclists and $8.2 \%$ were pedestrians. Drivers and passengers made up for $72.1 \%$ and $27.9 \%$ of the subjects with traumatic spine.

Wang et al. demonstrated that in China, patients involved in motor vehicle accidents were car drivers (27.1\%), pedestrians injured by cars $(22.2 \%)$, and car passengers $(20.8 \%)$ [17]. In our study $84.3 \%$ of the accidents occurred in cities, while $10.2 \%$ and $5.5 \%$ of them occurred in villages and highways, respectively. Thurman et al. reported that $55 \%$ of accidents occurred in urban areas, notwithstanding $45 \%$ occurring in rural places [21]. Moreover, $26 \%$ of the accidents occurred in highways and $74 \%$ in roads or streets [21].

Anatomical locations of $\mathrm{SCl}$ in our study were cervical (42.5\%), lumbar $(30.7 \%)$, thoracic $(18.1 \%)$, thoracic and lumbar $(5.7 \%)$, thoracic and cervical $(2.4 \%)$, lumbar and cervical $(0.8 \%)$ regions. O'Corner's [22] reported that $\mathrm{SCl}$ occurred mostly in the cervical region, [particularly in $\mathrm{C} 4$ (18\%), C5 (17\%), and C6 (9\%)], lumbar region [L1 (11\%)], and lower thoracic region [T12 (6\%)]. In a study carried out by Thompson et al. [23], 831 patients with traumatic spine were assessed and $63.4 \%$ of the injuries was found in cervical region, as well as $26.5 \%$ in thoracic and $10.5 \%$ in lumbar regions. Thurman et al. illustrated that $\mathrm{Cl}-\mathrm{C} 4 \mathrm{SCl}$ was in $43 \%$ of their cases, in addition $40 \%$ of $\mathrm{SCl}$ in $\mathrm{CS}-\mathrm{C6}$ [21]. The remaining cervical $\mathrm{SCl}$ affected segments below $\mathrm{C6}(8 \%)$ or did not have a precise neurologic deficit (9\%). Moreover, $27 \%$ of $\mathrm{SCl}$ involved thoracic spinal cord; $13 \%$ involved lumbar segments; and $1 \%$ involved sacral segments.

In our study, $83.8 \%$ of the patients used no safety devices; $15.3 \%$ used safety belts; and $0.8 \%$ used helmet. Stein's et al. pointed out that amongst patients with cervical $\mathrm{SCl}$ and spinal column SCl, $64.4 \%$ used safety belts [24]. They also reported that $67.4 \%$ of the patients deployed airbag. We observed that $93.7 \%, 4.7 \%$, and $1.6 \%$ of our patients had $\mathrm{GCS} \geq 13, \mathrm{GCS}<9$, and $9 \leq \mathrm{GCS} \leq 12$, respectively. Moreover, $94.5 \%$ of patients had no cardiovascular co-disease, while $3.9 \%, 0.8 \%$, and $0.8 \%$ had high blood pressure, stroke, and palpitation, respectively. Chamberlain's et al. [25] found that persons with $\mathrm{SCl}$ experienced mortality rates due to cardiovascular disease 2.7 times greater than that of the general population. In the present study, $99.2 \%$ of the patients was found to have no respiratory diseases and $0.8 \%$ of them had asthma.

Furthermore, most of the patients had no complications in their hospital stay and $2.4 \%$ experienced fever and CSF leakage. The Mean $\pm S D$ VAS score of the patients in our study was $5.39 \pm 1.14$. The Mean $\pm S D$ duration of hospitalization in ICU was $6.4 \pm 10$ days (Median=2 days, range $=35$ days). In a study performed by Galicia et al. [26], during 1995- 2014, $41.2 \%$ of their patients were hospitalized in ICU. Elsewhere, Maharaj showed that the median ICU length of stay was 3 days [27]. In this study approximately $90 \%$ of patients were discharged with good recovery according to GOS.

\section{Conclusion}

The evidence from the present study suggests that spine trauma due to MVA is mostly seen in the young. SCl due to such trauma was mostly found in the cervical region. Good recovery was seen in most of the subjects. Understanding the epidemiology of TSCI due to MVAs can be helpful for healthcare providers planning preventative strategies.

\section{Ethical Considerations}

Compliance with ethical guidelines

The study was approved by institutional ethics committee (IR.GUMS.REC.1397.518)

Funding

This research did not receive any specific grant from funding agencies in the public, commercial, or not-for-profit sectors.

\section{Authors contributions}

Sasan Andalib and Zahra Mohtasham Amiri (co-first authors) contributed equally to the paper. All authors met ICMJE criteria.

\section{Conflict of interest}

The authors declare no conflict of interest with respect to the present paper.

\section{Acknowledgements}

We thank Guilan Road Trauma Research Center for its support. 


\section{References}

[1] Emamhadi M, Soltani B, Yousefzadeh-Chabok S, Babaee P, Behzadnia H, Ghadarjani S, et al. Evaluation of mesenchymal stem cells and granulocyte colony stimulating factor in treatment of complete spinal cord injury. Journal of Experimental and Clinical Neurosciences. 2018; 5(1):1-5.

[2] Ning GZ, Wu Q, Li YL, Feng SQ. Epidemiology of traumatic spinal cord injury in Asia: A systematic review. The Journal of Spinal Cord Medicine. 2012; 35(4):229-39. [DOI:10.1179/2045772312Y.0000000021] [PMID] [PMCID]

[3] Chiu WT, Lin HC, Lam C, Chu SF, Chiang YH, Tsai SH. Epidemiology of traumatic spinal cord injury: Comparisons between developed and developing countries. Asia Pacific Journal of Public Health. 2010; 22(1):9-18 [DOI:10.1177/1010539509355470] [PMID]

[4] Ge L, Arul K, Ikpeze T, Baldwin A, Nickels JL, Mesfin A. Traumatic and nontraumatic spinal cord injuries. World Neurosurgery. 2018; 111:e142-8. [DOI:10.1016/j.wneu.2017.12.008] [PMID]

[5] World Health Organization. Society ISC. International perspectives on spinal cord injury. Geneva: World Health Organization Press; 2013.

[6] Lidal IB, Snekkevik H, Aamodt G, Hjeltnes N, Biering-Sorensen F, Stanghelle JK. Mortality after spinal cord injury in Norway. Journal of Rehabilitation Medicine. 2007; 39(2):145-51. [DOI:10.2340/16501977-0017] [PMID]

[7] Ahuja CS, Wilson JR, Nori S, Kotter MRN, Druschel C, Curt A, et al. Traumatic spinal cord injury. Nature Reviews Disease Primers. 2017; 3:17018. [DOI:10.1038/nrdp.2017.19] [PMID]

[8] Yashon D. Spinal injury. New York: Appleton \& Lange; 1986.

[9] White NH, Black NH. Spinal Cord Injury (SCl) facts and figures at a glance. Birmingham: National Spinal Cord Injury Statistical Center, Facts and Figures at a Glance; 2016. [DOI:10.1179/1079026812Z.00000000063] [PMID] [PMCID]

[10] Hagen EM, Rekand T, Gilhus NE, Grønning M. Traumatic spinal cord injuries-incidence, mechanisms and course. Tidsskrift for Den Norske Lægeforening Tidsskrift for Praktisk Medicin, Ny Raekke. 2012; 132(7):831-7. [DOI:10.4045/ tidsskr.10.0859] [PMID]

[11] Sharif-Alhoseini M, Rahimi-Movaghar V. Hospital-based incidence of traumatic spinal cord injury in tehran, iran. Iranian Journal of Public Health. 2014, 43(3):331-41. [PMID] [PMCID].

[12] Proctor MR. Spinal cord injury. Critical Care Medicine. 2002; 30(11):S48999. [DOI: 10.1097/01.CCM.0000034132.14832.6D

[13] Robertson A, Branfoot T, Barlow IF, Giannoudis PV. Spinal injury patterns resulting from car and motorcycle accidents. Spine. 2002; 27(24):2825-30. [DOI:10.1097/00007632-200212150-00019] [PMID]

[14] Ramezani S, Mohtasham-Amiri Z, Kouchakinejad-Eramsadati L, Shokatjali $\mathrm{H}$, Yousefzadeh-Chabok S. Epidemiology of traumatic spinal fractures and spinal cord injuries in Guilan, north of Iran. Caspian Journal of Health Research 2019; 4(1):12-5. [DOI:10.29252/cjhr.4.1.12]

[15] Andalib S, Mohtasham Amiri Z, Yousefzadeh-Chabok S, Saberi A, Reihanian $Z$, Kouchakinejad Eramsadat L, et al. Epidemiology of spine trauma and spinal cord injuries in the north of Iran. Iranian Journal of Neurosurgery. 2019; 4(4) In Press. [DOI:10.32598/irjns.4.4.180]

[16] Najimi-Varzaneh A, Gholami Fesharaki M. Prevalence of road traffic accidents in Iran: A systematic review, GIS and meta-analysis. Iran Red Crescent Medical Journal. 2018; 20(10):e83852. [DOI:10.5812/ircmj.83852]

[17] Wang H, Liu X, Zhao Y, Ou L, Zhou Y, Li C, et al. Incidence and pattern of traumatic spinal fractures and associated spinal cord injury resulting from motor vehicle collisions in China over 11 years: An observational study. Medicine.
2016; 95(43):e5220. [DOI:10.1097/MD.0000000000005220] [PMID] [PMCID]

[18] Taghippor M, Sherafat Kazemzadeh E. [Column and spinal cord injuries in Shiraz Nemazi hospital, an epidemiological study (Persian)]. Armaghane-eDanesh. 2006; 10(4):55-62.

[19] Fakharian E, Tabesh H, Masoud S. [An epidemiologic study on spinal injuries in kashan (Persian)]. Journal of Guilan University of Medical Sciences. 2004; 13(49):80-5.

[20] Yousefzadeh Chabok S, Safaee M, Alizadeh A, Ahmadi Dafchahi M, Taghinnejadi $O$, Koochakinejad L. Epidemiology of traumatic spinal injury: a descriptive study. Acta Medica Iranica. 2010; 48(5):308-11. [PMID]

[21] Thurman DJ, Burnett CL, Beaudoin DE, Jeppson L, Sniezek JE. Risk factors and mechanisms of occurrence in motor vehicle-related spinal cord injuries: Utah. Accident Analysis \& Prevention. 1995; 27(3):411-5. [DOI:10.1016/0001 4575(94)00059-U] [PMID]

[22] O'Connor P. Incidence and patterns of spinal cord injury in Australia. Accident Analysis \& Prevention. 2002; 34(4):405-15. [DOI:10.1016/S0001 4575(01)00036-7] [PMID]

[23] Thompson C, Mutch J, Parent S, Mac-Thiong JM. The changing demographics of traumatic spinal cord injury: An 11-year study of 831 patients. The journal of Spinal Cord Medicine. 2015; 38(2):214-23. [DOI:10.1179/204577231 4Y.0000000233] [PMID] [PMCID]

[24] Stein DM, Kufera JA, Ho SM, Ryb GE, Dischinger PC, O'Connor JV, et al. Occupant and crash characteristics for case occupants with cervical spine injuries sustained in motor vehicle collisions. The Journal of Trauma. 2011; 70(2):299309. [DOI:10.1097/TA.0b013e3181f8aa91] [PMID]

[25] Chamberlain JD, Buzzell A, Gmunder HP, Hug K, Jordan X, Moser A, et al. Comparison of all-cause and cause-specific mortality of persons with traumatic spinal cord injuries to the general swiss population: Results from a national cohort study. Neuroepidemiology. 2019; 52(3-4):205-13. [DOI:10.1159/000496976] [PMID]

[26] Montoto-Marques A, Ferreiro-Velasco ME, Salvador-de la Barrera $S$ Balboa-Barreiro V, Rodriguez-Sotillo A, Meijide-Failde R. Epidemiology of traumatic spinal cord injury in Galicia, Spain: Trends over a 20-year period. Spinal Cord. 2017; 55(6):588-94. [DOI:10.1038/sc.2017.13] [PMID]

[27] Maharaj MM, Stanford RE, Lee BB, Mobbs RJ, Marial O, Schiller M, et al. The effects of early or direct admission to a specialised spinal injury unit on outcomes after acute traumatic spinal cord injury. Spinal Cord. 2017; 55(5):518-24. [DOI:10.1038/sc.2016.117] [PMID] 